\title{
Association of Cigarette Smoking with Thickness of Intimal Layer of Carotid Arteries on Color Doppler Ultrasound Study and Its Surgical Management
}

\author{
RANA ZUBAIR MAHMOOD ${ }^{1}$, A. M. YASIN KHAN ${ }^{2}$, SIKANDAR ALI ${ }^{1}$ \\ SHOQAIB MEHMOOD ${ }^{1}$, FAHEEM AHMAD USMANI ${ }^{1}$, SAIRA BILAL ${ }^{2}$ \\ ${ }^{1}$ Department of Neurosurgery, Lahore General Hospital \\ ${ }^{2}$ Departments of Diagnostic Radiology \& Neuroradiology, Lahore General Hospital, Lahore - Pakistan \\ DOI 10.36552/pjns.v24i2.453
}

\begin{abstract}
Objectives: Aim of this study is to evaluate the intimal vessel wall thickness in smoker and their co-relation with non-smoker and also surgical management of stenosis.
\end{abstract}

Material and Methods: It is a prospective study of 55 cases. Study span and follow up duration were 4 months. Our patients were presented with the history of CVA (Cerebrovascular accident), hypertension, diabetes, and headache.

Results: In all patients, the carotid doppler ultrasound was done and their intimal vessel wall thickness was noted. Our $78 \%$ patients were smoker and non-smoker was $22 \%$. In our study, $52 \%$ patients had CVA, $41 \%$ patients had hypertension, 30\% patients had headache and 9\% patients were also obese. Forty three smokers used to take 15 - 25 cigarettes daily. Among 43 patients, 5 patients were females. In carotid Doppler study, intimal thickness was increased in 87\%, the plaque was observed in 49\% and stenosis was observed in 38\% cases. In $18 \%$ patients, who had stenosis > 70\%, carotid endarterectomy was performed and in rest of the patients medical treatment done. Patients who were chronic smokers and had medical co-morbidities showed greater thickness of intimal layer of vessels on carotid Doppler. In 6 patients, post-operative headache occurred.

Conclusion: Smokers had more thickness of intimal layer of carotid vessels. Carotid endarterectomy yields good results in case of stenosis more than $70 \%$.

Keywords: Cerebrovascular accident, Intimal layer thickness, Carotid doppler ultrasound, Cigarette smoking.

\section{INTRODUCTION}

The carotid arteries are crucial vessels supplying blood to head, neck and brain. Right common carotid artery arises from brachiocephalic trunk and left common carotid artery arise from the aortic arch. These common carotid arteries are further sub-divided into external and internal carotid arteries. Furthermore, external and internal carotid arteries can be differentiated on many basis during USG examination like blood blow wave pattern, branches and anatomical orientation. ${ }^{1}$

Like other vessels of our body, the carotid vessels are composed of three layers, i.e., intima, media, and adventitia. Our main concern here was an intimal wall thickness measurements in association with a history of smoking. At the bifurcation of CCA (Common carotid artery) special sensors were present, i.e., baroreceptors in the carotid. These sensors have important role in regulation of blood pressure. While performing an ultrasound of carotid system, it is important to have an orientation of internal jugular vein as well. ${ }^{2}$

Smoking is considered to be associated with vessels pathology, especially in the development of 
ischemic stroke. Although, other risk factors like diabetes, HTN, Obesity etc. have also a significant role in the vessel pathology. Smokers are more prone to vessel disease in comparison to non-smokers.

Other related risk factors, especially type-2 DM are also found susceptible to atherosclerotic changes in the vessels. Intima and media thickness of CCA has been assessed to be higher in patients presenting with a history of $\mathrm{DM}$ and are more prone to ischemic stroke. ${ }^{3,4,5}$

Vasculitis is inflammation of vessels due to infection, traumatic injury or autoimmune disease. We suspect vasculitis, while performing carotid doppler ultrasound examination as it becomes tender on palpation with an ultrasound probe. ${ }^{6,7}$ In stroke, the patients used to present with clinical pictures of sudden deterioration of vision, weakness of any part of body. ${ }^{8}$

We diagnosed the stroke on the basis of history, clinical examination of CNS and CT scan. Unfortunately a lot of patients come for carotid doppler scan after hemorrhagic stroke.

Doppler ultrasonography is an attractive way of assessment of carotid system, being non-invasive, affordable, less time consuming. It is nowadays widely used to studythe carotid arteries for evaluation of atherosclerotic changes in the vessels, plaque formation, hemodynamic study like velocity, and even the percentage of stenosis. For this purpose, the carotid doppler ultrasound parameters, i.e., pulsatility index (PI), resistive index and SD ratio, lumen diameter, blood flow pattern are parameters for evaluation of vessels.

\section{MATERIAL AND METHODS}

\section{Study Design}

It was a prospective observational study.

\section{Inclusion Criteria}

We included 55 patients who were presented in Lahore General Hospital Lahore diagnostic radiology department. Study span was 4 months and follow-up period was also 4 months.

\section{Exclusion Criteria}

Previously operated cases who did not gave the consent.

Carotid Doppler ultrasound was performed with linear transducer. The patients were lying supine on the table, while head slightly turned towards opposite and with slightly extended position. Doppler ultrasound was performed on both sides and results were compared.

\section{Data Collection}

All data was collected on special designed proforma previous operated case and who did not gave concert.

\section{RESULTS}

\section{Age Incidence}

The age range was $21-69$ years and average age was 45 years.

\section{Gender Distribution}

The 34 patients were male and 21 patients were female.

\section{Diagnostic Procedures}

In all patients diagnostic tool was carotid Doppler ultrasound on the presentation and on follow-up

Table 1: Percentage Disorder in Smoker and Non-smoker.

\begin{tabular}{|l|c|c|c|}
\hline $\begin{array}{l}\text { Association } \\
\text { with Smoking }\end{array}$ & $\begin{array}{c}\text { No of } \\
\text { Patients }\end{array}$ & $\begin{array}{c}\text { Age } \\
\text { (Years) }\end{array}$ & Percentage \\
\hline Smoker & 43 & $21-69$ & $78 \%$ \\
\hline Non-smoker & 12 & $30-56$ & $22 \%$ \\
\hline Total & 55 & $21-69$ & $100 \%$ \\
\hline
\end{tabular}

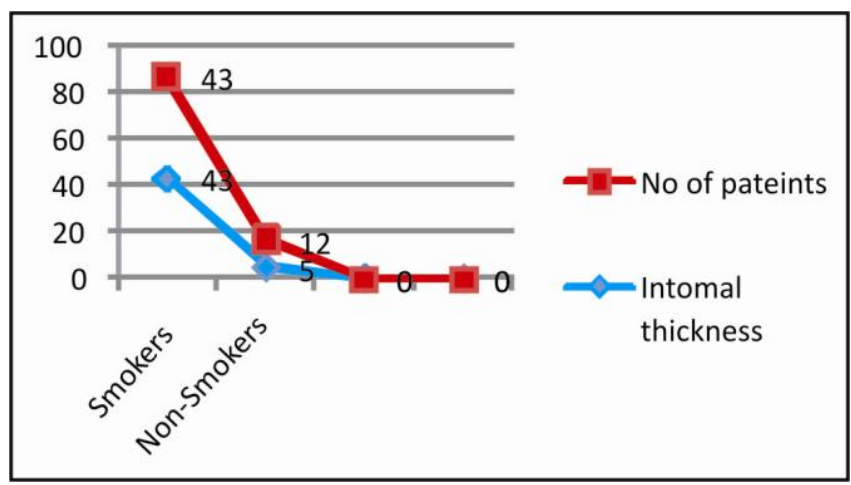

Fig. 1: Graphical Presentation of 43 Smoker and 12 Nonsmokers among Them 43 Smokers and 5 Nonsmokers had Increased Intimal Thickness. 
period. In carotid Doppler ultrasound we saw carotid vessel lumen, the velocity of blood flow, intimal wall changes, atherosclerotic plaques and percentage of the stenosis of vessel lumen.

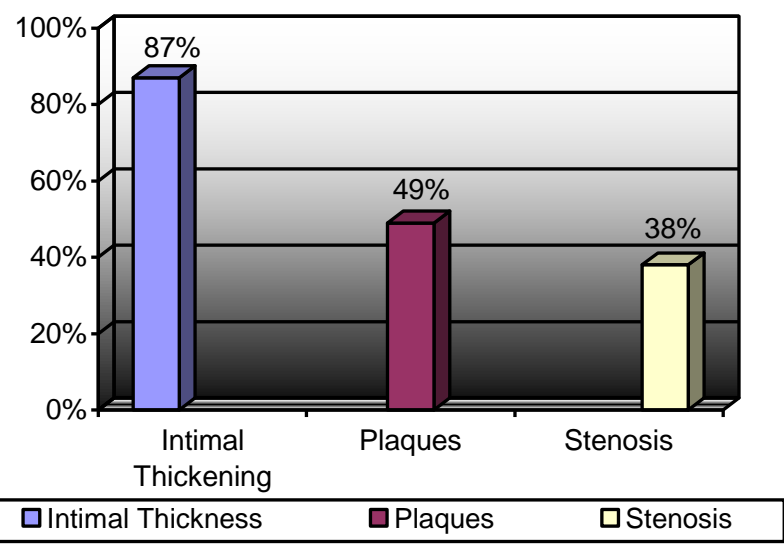

Fig. 2: Graphical Demonstration of Percentage of Findings.

Table 2: Percentage of Finding in Our Carotid Doppler Study.

\begin{tabular}{|l|c|c|}
\hline Outcome & No of Patients & Percentage \\
\hline Intimal thickness & 48 & $87 \%$ \\
\hline Plague & 27 & $49 \%$ \\
\hline Stenosis & 21 & $38 \%$ \\
\hline
\end{tabular}

Table 3: Risk Factors in Patients in Our Study.

\begin{tabular}{|l|c|c|}
\hline Risk Factors & Number & Percentage \% \\
\hline Smoking & 43 & 78 \\
\hline Headache & 17 & 30 \\
\hline Hypertension & 23 & 41 \\
\hline Diabetes & 7 & 12 \\
\hline CVA & 29 & 52 \\
\hline
\end{tabular}

\section{DISCUSSION}

A carotid artery aneurysm is a dilatation of any part of carotid vessels and usually noticed on advance MRA, CTA scans in our setup. If such dilatation develops, it becomes a weak area to be predisposed to sudden rupture. $^{11,12}$ In Lahore General Hospital Lahore, a special unit of Neuro-interventional radiology has been established, where patients of aneurysms from throughout the country are referred. Carotid endarterectomy is used to treat the patients having stenosis above $70 \% .^{139}$ Different studies also indicate that in patients of smoking, diabetes, hypertension, intimal layer thickness increases as the duration of smoking is increased. ${ }^{9}$

In cholesterol plaque, sometimes if the break can dislodge in the form of embolism into vessels in head causing stroke. Stenotic vessels due to cholesterol plaque formation or atherosclerotic changes can also compromise adequate flow to brain tissues. ${ }^{10}$

We consulted Neuroradiology and Neurosurgery department for the management of intimal wall thickness, plaque formation and stenosis of the carotid artery. In our study, we had 34 male patients, i.e., $61 \%$ and 21 female patients, i.e., $38 \%$. Male to female ratio was $1: 6$

Out of 55 patients, our 17 patients presented with complaint of headache, 23 patients presented with complaint of hypertension, 7 patients with diabetes, 5 presented with obesity and 29 patients presented with history of CVA.

In our study, 43 patients, i.e., $78 \%$ were smokers and 12 were non-smokers, i.e. $21 \%$. The age range in smokers was 21-69 years and in non-smoker it was $30-56$ years. All smokers have changes in changes in the vessel wall. Among non-smoker, i.e., out of 12 our 5 patients had normal vessel wall.

In our study, the risk factors were smoking, headache, hypertension, diabetes, CVA and obesity. Our 43 (78\%) patients were smokers, 17 (30\%) patients had headache, $23(41 \%)$ patients had hypertension, 7 (12\%) patients had diabetes, 29 (52\%) patients had a CVA and $5(9 \%)$ patients had obesity. Out of 43 patients, 5 (9\%) patients were female smokers and $39(71 \%)$ patients were males.

In our 43 patients, 5 patients used to smoke less than 10 cigarettes daily, 20 patients used to smoke 15 - 20 cigarettes daily and 13 patients used to smoke 20 - 25 cigarettes daily. Intimal thickness was observed in 48 patients, i.e. $87 \%$, a plaque was noted in 27 patients, i.e. $49 \%$ and stenosis was seen in 21 patients, i.e. $38 \%$.

Our 10 patients had carotid artery stenosis $70-$ $90 \%$ with plaque formation. In these patients carotid endarterectomy was performed. These patients improved and in the follow up period of 4 months no stroke was observed in any patient. Rest of the patients who had plaque formation in carotid vessels are managed conservatively. 
Our 6 patients had post-operative headache due to reperfusion syndrome, which was managed medically and the results were good in follow-up period of 4 months.

Our 5 patients had $60-70 \%$ stenosis in the carotid artery. They presented with chronic stenosis and also had medical co-morbidities. In these patients, medical management was done and the prognosis was not good and they deteriorated.

Carotid Doppler ultrasound was performed in all patients to see changes in the vessel wall. In carotid doppler main positive findings, which we observed were intima of the vessel wall, plaque and stenosis in vessels.

All these patients were taking treatment for their disorders. On follow up, again we did a carotid doppler ultrasound. We observed that those patients who showed compliance to their treatment and quit smoking, had improvement in vessel wall thickness.

Prior studies demonstrated that there is no difference in intimal layer thickness of the carotid arteries on doppler scan in smoker and nonsmokers. ${ }^{14,15}$ Other studies showed that there is a remarkable difference in intimal layer thickness of carotid arteries in smokers. ${ }^{16,17}$

\section{CONCLUSION}

It is concluded that smoking had strong co-relation with intimal layer thickness. Because in our study, we observed all smokers had increased thickness in intimal layer of the vessel wall. If we quit smoking and control our risk factors, then we can significantly decrease pathology of the vessel wall. And, carotid endarterectomy is the best option available to treat the patients having stenosis more than $70 \%$ and those who had no medical co-morbidities.

\section{REFERENCES}

1. Ashrafian $\mathrm{H}$. Anatomically specific clinical examination of the carotid arterial tree. Anatomical Science International, 2007: 82 (1): 16-23.

Doi:10.1111/j.1447-

073X.2006.00152.x. PMID 17370446.

2. Wallbach, M; Koziolek, MJ. Baroreceptors in the carotid and hypertension-systematic review and metaanalysis of the effects of baroreflex activation therapy on blood pressure. Nephrology, Dialysis, Transplantation, 2017; 33 (9): 1485-1493. Doi:10.1093/ndt/gfx279. PMID 29136223.

3. Kathiresan S, Srivastava D. Genetics of human cardiovascular disease. Cell, 2012; 148 (6): 1242- 57.
Doi: 10.1016/j.cell.2012.03.001. PMC 3319439. PMID 22424232.

4. Tunstall-Pedoe H. Cardiovascular Risk and Risk Scores: ASSIGN, Framingham, QRISK and others: how to choose. Heart. 2011; 97 (6): 442-444.

5. Cohen BE, Edmondson D, Kronish IM. State of the Art Review: Depression, Stress, Anxiety, and Cardiovascular Disease. American Journal of Hypertension, 2015; 28 (11): 1295-302.

Doi:10.1093/ajh/hpv047. PMC 4612342. PMID 259116 39.

6. Overview of Vasculitis. Archived from the original on 3 April 2015. Retrieved 5 October 2016.

7. The Johns Hopkins Vasculitis Center - Symptoms of Vasculitis. Archived from the original on 27 February 2009. Retrieved 7 May 2009.

8. Who Is at Risk for a Stroke? www.nhlbi.nih.gov. March 26, 2014. Archived from the original on 27 February 2015. Retrieved 27 February 2015.

9. Medline Plus. Carotid duplex Update Date: 5/12/2009. Updated by: Benjamin Taragin M.D.

10. Spence JD. Technology Insight: ultrasound measurement of carotid plaque--patient management, genetic research, and therapy evaluation. Nature Clinical Practice. Neurology, 2006; 2 (11): 611-9.

Doi: 10.1038/ncpneuro0324. PMID 17057748.

11. Brain Aneurysm Basics | The Brain Aneurysm Foundation. Bafound.org. Archived from the original on 2014-05-30. Retrieved 2014-05-30.

12. Liepsch, D.; Sindeev, S.; Frolov, S. "An impact of nonNewtonian blood viscosity on hemodynamics in a patient-specific model of a cerebral aneurysm". Journal of Physics: Conference Series. 2018; 1084: 012001. Doi: 10.1088/1742-6596/1084/1/012001. ISSN 17426596.

13. Friedman SG. The first carotid endarterectomy. Journal of Vascular Surgery, 2014; 60 (6): 1703-8.e1-4. Doi: 10.1016/j.jvs.2014.08.059. PMID 25238726.

14. Pit'ha J, Krajickova D, Cifkova R, Hubacek J, Petrzilkova Z, Hejl Z, Stavek P, Skibova J, Poledne R: Intima-media thickness of carotid arteries in borderline hypertensives. J Neuroimaging, 1999; 9: 19-22.

15. Belcaro G, Laurora G, Cesarone MR, De Sanctis MT, Incandela L, Barsotti A: Progression of subclinical atherosclerosis in 6 years. Ultrasound evaluation of the average, combined femoral and carotid bifurcation intima-media thickness. Vasa. 1995; 24: 227-232.

16. an den Berkmortel FW, Smilde TJ, Wollersheim H, van Langen H, de Boo T, Thien T: Intima- media thickness of peripheral arteries in asymptomatic cigarette smokers. Atherosclerosis, 2000; 150: 397-401. Doi: 10.1016/S0021-9150(99)00391-3.

17. Joensuu T, Salonen R, Winblad I, Korpela H, Salonen JT: Determinants of femoral and carotid artery atherosclerosis. Journal of Internal Medicine, 1994; 236: 79-84. 


\section{Additional Information}

Disclosures: Authors report no conflict of interest.

Ethical Review Board Approval: The study was conformed to the ethical review board requirements.

Human Subjects: Consent was obtained by all patients/participants in this study.

Conflicts of Interest:

In compliance with the ICMJE uniform disclosure form, all authors declare the following:

Financial Relationships: All authors have declared that they have no financial relationships at present or within the previous three years with any organizations that might have an interest in the submitted work.

Other Relationships: All authors have declared that there are no other relationships or activities that could appear to have influenced the submitted work.

\section{AUTHORSHIP AND CONTRIBUTION DECLARATION}

\begin{tabular}{|l|l|l|}
\hline Sr.\# & Author's Full Name & Intellectual Contribution to Paper in Terms of: \\
\hline 1. & Rana Zubair & Study design and methodology. \\
\hline 2. & A.M Yasin Khan & Paper writing, referencing, data calculations and \\
\hline 3. & Sikandar Ali & Data collection and calculations \\
\hline 4. & Shoqaib Mehmood & Analysis of data and interpretation of results etc. \\
\hline 5. & Faheem Ahmad Usmani & Literature review and manuscript writing \\
\hline 6. & Saira Bilal & Analysis of data and quality insurer \\
\hline
\end{tabular}

Date of Submission: 17-4-2020

Date of Revision: 08-06-2020

Date of Online Publishing: 30-06-2020

Date of Print: 30-07-2020 